\title{
Familiaridade do ouvinte e inteligibilidade da pronúncia de aprendizes brasileiros de inglês
}

\author{
Neide Cesar Cruz (CRUZ, Neide Cesar) \\ Universidade Federal de Campina Grande - UFCG \\ neidecruz@uol.com.br
}

\begin{abstract}
Resumo
Este estudo focaliza a inteligibilidade da pronúncia de aprendizes brasileiros de Inglês Língua Estrangeira para dois grupos de ouvintes: um de falantes nativos da língua inglesa que não tinham familiaridade com o falar em inglês dos brasileiros e outro de falantes nativos do inglês familiarizados com o falar em inglês dos brasileiros. Especificamente, este estudo tencionou responder a duas questões: Quais desvios de pronúncia produzidos por aprendizes brasileiros de inglês afetaram a inteligibilidade da fala desses aprendizes quando apresentada para os dois grupos de ouvintes? e Para qual dos dois grupos de ouvintes a pronúncia dos aprendizes foi mais inteligível? Amostras contendo desvios de pronúncia, produzidos pelos aprendizes brasileiros de inglês, foram selecionadas e apresentadas aos dois grupos de ouvintes. Os resultados para cada grupo de ouvintes foram os seguintes: para o primeiro, desvios de acentuação de palavras, produção inapropriada de consoantes e desvios resultantes da interferência da grafia afetaram mais seriamente a inteligibilidade da fala dos aprendizes brasileiros; e para o segundo, apenas desvios de acentuação de palavras afetaram mais seriamente a inteligibilidade da fala dos aprendizes brasileiros. Portanto, a pronúncia dos aprendizes foi mais inteligível para o grupo familiarizado com o falar em inglês dos brasileiros.
\end{abstract}

Palavras-chave: pronúncia, inteligibilidade, aprendizes brasileiros de Inglês Língua Estrangeira (ILE)

\begin{abstract}
This study focuses on the pronunciation intelligibility of Brazilian learner's of English to two groups of listeners: native speakers of English unfamiliar with the way Brazilians pronounce English words and native speakers of English familiar with the way Brazilians pronounce English words. Specifically, this study was an attempt to answer the following two questions: Which features of mispronunciation in the speech of Brazilian learners of English affected their intelligibility when presented to the two groups of listeners? and To which group is the pronunciation of the Brazilian learners more intelligible? Samples containing features of mispronunciation produced by Brazilian learners of English were selected and presented to the two groups of listeners. The results for each group of listeners were as follows: for the first, misplaced word stress, inappropriate consonants and spelling pronunciation in the speech of the Brazilian learners affected their intelligibility more seriously than the other features; and for the second, only misplaced word stress affected the Brazilian learners' intelligibility. Therefore, the Brazilian learners' pronunciation was more intelligible to the group familiar with the way Brazilians pronounce English words.
\end{abstract}

Keywords: pronunciation, intelligibility, Brazilian learners of English as a Foreign Language (EFL). 


\section{Introdução}

Estudos em inteligibilidade de pronúncia, bem como discussões a respeito do tópico, têm sido incluídos na literatura há várias décadas (ABERCROMBIE, 1956; BAMGBOSE, 1998; CATFORD, 1950; FIELD, 2003; JENNER, 1996; JENKINS, 2000; KENWORTHY, 1987; SMITH; NELSON, 1985). Um dos aspectos discutidos refere-se à complexidade em se medir a inteligibilidade, devido ao grande número de variáveis que contribuem para facilitar ou impedir a inteligibilidade da fala de um aprendiz de língua estrangeira. Uma dessas variáveis está relacionada aos ouvintes, especificamente à familiaridade que eles têm com um sotaque estrangeiro em particular (SMITH; BISAZZA, 1982). Devido a essa familiaridade, estudos em inteligibilidade de pronúncia envolvendo diversos grupos de ouvintes precisam ser realizados, para que resultados mais confiáveis possam ser obtidos.

Tencionando responder a essa necessidade, este estudo focaliza a inteligibilidade da pronúncia de aprendizes brasileiros de Inglês Língua Estrangeira (ILE) para dois grupos de ouvintes. Os aprendizes brasileiros relataram ter os sotaques 'manezinho', 'paulistano', 'gaúcho' ou 'catarinense'. O primeiro grupo de ouvintes envolve vinte e cinco falantes nativos da língua inglesa residentes em Birmingham, Inglaterra, que não tinham familiaridade com o falar em inglês dos brasileiros. O segundo grupo de ouvintes consiste de doze falantes nativos do inglês, dez americanos e dois britânicos, residentes no Brasil, familiarizados com o falar em inglês dos brasileiros: os britânicos residiam na Inglaterra em Leeds e High Wycombe (Buckinghamshire)e os americanos residiam em lugares variados dos Estados Unidos: Englewood (Colorado), San Diego (California), Providence (Rhode Island), Silver Spring (Maryland), Princeton (New Jersey).

Especificamente, este estudo tenciona responder a duas questões: (1) Para qual dos dois grupos de ouvintes a pronúncia dos aprendizes é mais inteligível? e (2) Quais desvios de pronúncia produzidos por aprendizes brasileiros de inglês afetam a inteligibilidade da fala desses aprendizes quando apresentada para os dois grupos de ouvintes?

\section{Método}

\section{Coleta de dados}

A coleta de dados foi realizada em três etapas. Participaram da primeira etapa dez aprendizes brasileiros de ILE, matriculados nos cursos Extracurriculares da UFSC (Universidade Federal de Santa Catarina) ${ }^{1}$, que foram entrevistados por um falante nativo da língua inglesa de origem britânica. O nível de proficiência dos aprendizes variou entre o nível 5 (correspondendo ao intermediário) e o nível 8 (equivalente ao pós intermediário), e as idades variaram entre 18 e 24 anos. Entre os dez, somente dois nasceram e foram criados em Florianópolis, e relataram ter o sotaque caracterizado como 'manezinho'. Três deles nasceram e foram criados em São Paulo e relataram ter o

\footnotetext{
${ }^{1}$ Cursos extracurriculares são cursos livres de línguas oferecidos pela UFSC. Cada nível do curso tem a duração de um semestre, e inclui três horas de aulas semanais.
} 
sotaque 'paulistano'. Quatro nasceram e foram criados em lugares diferentes do estado de Santa Catarina e relataram ter os sotaques 'gaúcho' ou 'catarinense', ou 'manezinho'. Apenas um nasceu em Santarém, e foi criado em Florianópolis. Esse aprendiz relatou ter os sotaques 'paulistano' e 'catarinense'. Nenhum deles tinha tido experiência com a língua inglesa no exterior. Portanto, todo o conhecimento de inglês dos participantes, bem como a pronúncia dos mesmos, tinham sido adquiridos no Brasil.

As entrevistas foram gravadas em MD (minidisc) digital portátil Sony MZ-R37, com um microfone estéreo, a fim de assegurar uma alta qualidade na gravação. $O$ minidisc foi colocado perto dos aprendizes, para que as suas vozes pudessem ser ouvidas claramente. Quando os participantes foram convidados para participar da coleta de dados, sabiam que seriam gravados. Nenhum deles expressou preocupação a esse respeito. Cada entrevista durou de 12 a 18 minutos.

Trinta amostras (vide Anexo) contendo desvios de pronúncia, e não contendo desvios no nível gramatical e lexical (vide item "Variáveis relacionadas ao aprendizes" neste artigo), foram selecionadas das entrevistas, através de edição no programa Cool Edit. Em seguida, foram transferidas para um CD áudio, e apresentadas em um aparelho de CD para os dois grupos de ouvintes, que participaram da segunda e terceira etapas da coleta de dados.

A segunda etapa incluiu vinte e cinco ouvintes nativos do inglês, residentes em Birmingham, Inglaterra ${ }^{2}$. A idade dos ouvintes variou entre 20 e 65 anos, sendo 11 do sexo feminino e 14 do sexo masculino. Nenhum deles tinha profissão relacionada ao ensino de línguas e lingüística. Através de respostas dadas a um questionário, a falta de familiaridade dos ouvintes com o falar em inglês dos brasileiros foi confirmada, uma vez que brasileiros não foram incluídos entre os falantes de ILE que todos os ouvintes informaram ter contato. Portugueses também foram excluídos. Os ouvintes relataram que tinham contato principalmente com asiáticos e europeus falantes de ILE.

Os nativos ouviram cada amostra uma vez, já que inteligibilidade é considerada aqui como sendo a primeira impressão, e foram solicitados a: (1) avaliar o grau de inteligibilidade das amostras em uma escala de 1 a 6 , onde $1=$ impossível de entender e 6 = muito fácil de entender; e (2) transcrever as amostras. Ao final da coleta com esses ouvintes, gravamos uma conversa individual para que ele/ela pudesse oferecer explicações mais detalhadas a respeito da compreensão das amostras. A fim de obter mais uma confirmação da falta ou não de familiaridade desses ouvintes com o falar em inglês de brasileiros, solicitamos, no início da conversa, que eles deduzissem a nacionalidade dos falantes que tinham ouvido. Respostas a essa pergunta são apresentadas na análise dos dados (vide item “Análise qualitativa” neste artigo).

A terceira etapa da coleta de dados envolveu o segundo grupo de ouvintes: doze ouvintes nativos do inglês, dez americanos e dois britânicos, residentes, no período da coleta de dados, na Paraíba, especificamente em Campina Grande e em João Pessoa. As idades dos ouvintes variaram entre 19 e 28 anos, sendo 5 do sexo masculino e 7 do sexo feminino. Oito eram missionários e quatro estudantes do intercâmbio Rotary Internacional. O tempo que residiam no Brasil variava de seis meses a cinco anos e todos informaram que costumavam falar em inglês com brasileiros. Isso indica que os ouvintes tinham familiaridade com o falar em inglês dos brasileiros. Outras evidências dessa familiaridade são apresentadas na análise.

\footnotetext{
${ }^{2}$ A oportunidade de fazer um Doutorado Sandwich na Universidade de Birmingham, Inglaterra, por um período de 01 ano, com uma bolsa de estudos - CAPES - possibilitou a coleta de dados com os ouvintes britânicos.
} 
Assim como com os nativos participantes da segunda etapa da coleta de dados, os doze ouvintes ouviram cada amostra uma vez e foram solicitados a: (1) avaliar o grau de inteligibilidade das amostras em uma escala de 1 a 6 , onde $1=$ impossível de entender e 6 = muito fácil de entender; e (2) transcrever as amostras. Ao final da coleta gravamos uma conversa com cada um desses ouvintes, para que ele/ela pudesse oferecer explicações mais detalhadas a respeito da compreensão das amostras. Do mesmo modo como com os ouvintes do primeiro grupo, solicitamos, no início da conversa, que eles deduzissem a nacionalidade dos falantes que tinham ouvido. Respostas a essa pergunta são apresentadas na análise dos dados (vide item “Análise qualitativa” neste artigo).

Cada sessão com os dois grupos de ouvintes durou aproximadamente vinte minutos.

\section{Desvios de pronúncia}

A fim de identificarmos os desvios de pronúncia na fala dos aprendizes participantes da primeira etapa da coleta de dados, adotamos como guia os fonemas do inglês que são considerados difíceis para aprendizes brasileiros produzirem, e os sons que esses aprendizes pronunciam devido a essas dificuldades. Esses sons são identificados em quatro estudos - Mascherpe (1970), Lessa (1985), Lieff e Nunes (1993) e Baptista (2001).

Os desvios identificados e analisados aqui foram divididos em cinco categorias:

(1) desvios de acentuação de palavras, como em interesting [H(D) 㐁

(†) \& (J), acentuado na segunda sílaba;

(2) produção inapropriada de consoantes, think [ $\left.\chi^{\top}\right)(\downarrow \&$ \&], onde a fricativa dental / foi substituída pela labio-dental $\left[x^{\top}\right]$ e a nasal velar / $/$ / omitida, causando a nasalização da vogal anterior [ $($ (D)];

(3) produção inapropriada de vogais, $\sin [\bullet \mathcal{*}$ ], em que a vogal frontal [H] é produzida ao invés de/ $\mathrm{m} /$; /\&Z/; e

(4) epêntese, onde walk [• $2 \diamond \& \mathcal{E}$ (t] apresenta epêntese após a consoante velar

(5) desvios resultantes da interferência da grafia, onde o grafema $<1>$, correspondendo a um som mudo, é pronunciado como [ $\bullet$, no vocábulo talk $[\diamond 2 \diamond \&)$ \& $]$.

\section{Fundamentação teórica}

Abordaremos aqui dois aspectos relacionados à inteligibilidade. O primeiro diz respeito à definição para inteligibilidade que adotaremos no presente estudo. O segundo refere-se às variáveis envolvidas ao se medir inteligibilidade.

\section{Definição para inteligibilidade}

Várias terminologias e definições para inteligibilidade têm sido sugeridas por diversos autores. Adotaremos aqui a definição proposta por Smith e Nelson (1985). Inteligibilidade, segundo Smith e Nelson (1985, p. 334), refere-se ao "reconhecimento 
de palavras e elocuções”3. Essa definição é adequada à metodologia que adotamos, uma vez que o contexto situacional em que as amostras foram produzidas não é considerado. Isso significa que fatores relacionados ao discurso e à pragmática não serão abordados neste artigo. A inclusão desses fatores demandaria uma coleta de dados diferente daquela adotada neste estudo.

\section{Variáveis envolvidas em inteligibilidade}

Como mencionado na introdução, é extremamente difícil medir a inteligibilidade, devido ao número de variáveis que contribuem para facilitá-la ou impedi-la. Nesse caso abordaremos variáveis relacionadas ao grupo de aprendizes de ILE, e aos dois grupos de ouvintes para quem a inteligibilidade da fala dos aprendizes foi investigada.

\section{Variáveis relacionadas aos aprendizes}

Duas variáveis relacionadas ao grupo de aprendizes foram consideradas. A primeira diz respeito a erros gramaticais. Segundo Tomiyama (1980), erros gramaticais podem afetar a inteligibilidade da fala de aprendizes de uma língua estrangeira. O autor investigou a relação entre erros gramaticais e quebras na comunicação. Especificamente, o objetivo do seu estudo foi investigar quais dos erros gramaticais omissão, inserção ou escolhas inadequadas de artigos e conectivos - afetam a comunicação entre aprendizes de inglês língua estrangeira e falantes nativos do inglês. Resultados estatísticos sugerem que erros de artigos foram menos cruciais para a comunicação do que conectivos.

A segunda variável refere-se aos erros lexicais. Wang (1987) realizou um estudo para medir a inteligibilidade da fala de estudantes universitários da Malásia, falantes de inglês como segunda língua, para ouvintes britânicos. Os seguintes aspectos foram investigados: erros de pronúncia, erros no nível sintático, erros lexicais e fatores extralingüísticos no nível do discurso. Resultados quantitativos mostram os erros que afetaram mais seriamente a inteligibilidade da fala dos estudantes. Esses erros, em ordem decrescente de relevância, são os seguintes: fatores extra-lingüísticos no nível do discurso; erros segmentais; erros no nível sintático; erros supra segmentais; e erros lexicais. O estudo de Wang demonstra, portanto, que erros no nível lexical podem afetar a inteligibilidade de falantes de inglês como segunda língua para ouvintes nativos.

Os resultados dos dois estudos mencionados indicaram-nos a necessidade de selecionar, das entrevistas dos aprendizes participantes deste estudo, amostras que não contivessem nem erros gramaticais, nem erros no nível lexical. Por essa razão, como mencionado na metodologia (vide item “Coleta de dados” neste artigo), as trinta amostras apresentadas aos dois grupos de ouvintes deste estudo contêm apenas desvios de pronúncia.

\section{Variáveis relacionadas aos ouvintes}

A variável considerada aqui refere-se à familiaridade do ouvinte com um sotaque estrangeiro em particular.

\footnotetext{
3 “word/utterance recognition”
} 
Smith e Bisazza (1982) investigaram a compreensão da fala de falantes de inglês com três sotaques diferentes - americano, indiano e japonês - para nativos e nãonativos da língua inglesa, que residiam em sete países diferentes. Um falante do sexo masculino de cada sotaque - um americano, um indiano e um japonês - foi gravado lendo três formas diferentes do Teste Michigan de Compreensão Oral (MTAC). As gravações foram enviadas para 207 avaliadores, que foram divididos em três grupos. O primeiro abrangeu falantes de Inglês como Segunda Língua (ISL) de Hong Kong, Índia, e Filipinas; o segundo incluiu falantes de ILE do Japão, Taiwan e Tailândia; o terceiro envolveu falantes que têm inglês como língua materna, residentes no Havaí. Aos avaliadores foram solicitadas duas atividades: (1) deduzir a nacionalidade dos falantes; e (2) avaliar o grau de dificuldade para compreendê-los. Os resultados mostram que os avaliadores entenderam melhor os sotaques com os quais tinham mais exposição. Baseando-se nesses resultados, Smith e Bisazza (1982, p. 269) argumentam que "o inglês de alguém é mais compreensível para aqueles que têm exposição ativa a esse inglês"4.

Field (2003) também menciona a familiaridade do ouvinte com o sotaque do falante como um fator que facilita a inteligibilidade. O autor ilustra o seu argumento utilizando falantes nativos do inglês, especificamente os que têm o sotaque da cidade de Newcastle. Segundo Field, falantes nativos de Newcastle podem não ser inteligíveis para ouvintes britânicos residentes no sul da Inglaterra. Isso não significa, argumenta Field, que o sotaque de Newcastle é difícil de ser entendido, mas mostra a falta de exposição dos ouvintes do sul a esse sotaque. Se esses ouvintes decidirem morar em Newcastle, e forem expostos aos falantes desse lugar, eles terão a possibilidade de acumular traços mentais do referido sotaque e, em algum tempo, serão capazes de reconhecer o que ouvirem.

No presente estudo, os dois grupos de ouvintes têm características diferentes com relação à familiaridade com o falar em inglês dos aprendizes brasileiros participantes. O primeiro grupo residia na Inglaterra, e relataram não ter tido contato com brasileiros e portugueses falantes de ILE. O segundo grupo de nativos já residia no Brasil há algum tempo, e, como mencionado na metodologia, costumava falar em inglês com brasileiros.

\section{Análise e resultados}

Apresentaremos os resultados quantitativos e qualitativos relativos aos dois grupos de ouvintes.

\section{Análise quantitativa}

Nesta seção, descreveremos o resultado da correlação das avaliações feitas pelos ouvintes e os desvios de pronúncia que mais afetaram a inteligibilidade da fala dos aprendizes brasileiros para os dois grupos de ouvintes. Correlação refere-se a uma associação numérica entre duas variáveis (BARBETTA, 2003).

Correlação entre os ouvintes

\footnotetext{
4 “one's English is more comprehensible to those people who have had active exposure to it”.
} 
A correlação entre os ouvintes foi medida através da correlação de Pearson. Os resultados foram positivos para os dois grupos de ouvintes. O valor do coeficiente máximo para o primeiro grupo foi $r=0,86$; para o segundo grupo foi $r=0,88$. Esses números revelam, portanto, que a correlação para os dois grupos foi alta.

A Figura 1 representa e ilustra a síntese das correlações para o primeiro grupo de ouvintes:

Figura 1

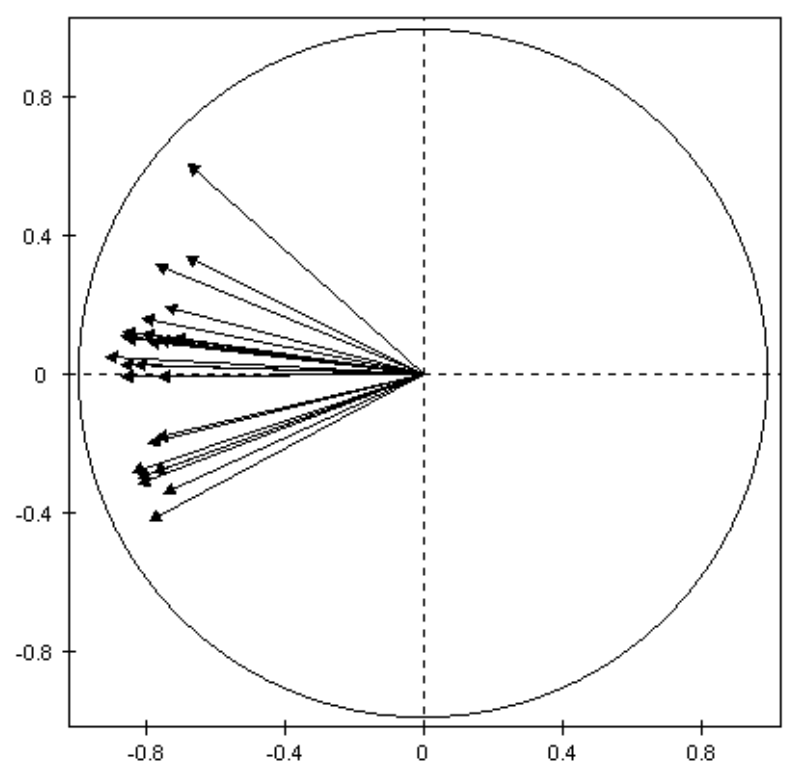

Figura 1. Síntese do coeficiente de correlação.

A Figura 1 é chamada círculo de correlação, e representa a correlação de todas as avaliações dadas na escala de 1 a 6 pelos ouvintes do primeiro grupo. Os dois grupos de setas, localizadas na parte superior e inferior do círculo, incluem as avaliações de cada ouvinte. Uma vez que o primeiro grupo envolveu 25 ouvintes, há, portanto, 25 setas. Como podemos observar, as setas apontam para a mesma direção, indicando uma correlação positiva entre elas. Uma vez que os ângulos entre as setas são pequenos, as correlações são consideradas altas.

Desvios de pronúncia e avaliação dos ouvintes

Com o objetivo de identificar quais desvios de pronúncia produzidos pelos aprendizes brasileiros de inglês afetam a inteligibilidade da fala desses aprendizes quando apresentada para os dois grupos de ouvintes, o coeficiente de correlação entre o número total de desvios nas cinco categorias - (1) desvios de acentuação de palavras; (2) produção inapropriada de consoantes; (3) produção inapropriada de vogais; (4) epêntese e (5) desvios resultantes da interferência da grafia - e as avaliações dos ouvintes foram calculadas para investigar a relação entre essas duas variáveis. O número total de desvios de pronúncia em cada uma das cinco categorias é apresentado a seguir em ordem decrescente: (1) produção inapropriada de vogais = 115; (2) produção inapropriada de consoantes $=66$; (3) desvios resultantes da interferência da grafia $=21$; (4) epêntese $=12$; e (5) desvios de acentuação de palavras $=7$. Esses valores foram 
organizados em intervalos diferentes, cada um deles incluindo um número variado de desvios de pronúncia ${ }^{5}$. O objetivo do procedimento estatístico foi encontrar o efeito, nas avaliações dos ouvintes, dos desvios de pronúncia agrupados em intervalos. ANOVA foi aplicado. ANOVA calcula a média das avaliações em cada intervalo, e determina o contraste existente entre elas.

Os resultados para os dois grupos de ouvintes são descritos a seguir. Para o primeiro grupo de ouvintes, entre as cinco categorias, três foram significativas, e são mostradas aqui em ordem decrescente de significância: desvios de acentuação de palavras $(F=7,885 ; p<0,01)$, desvios resultantes da interferência da grafia $(F=4,661 ; p$ $<0,05)$, e produção inapropriada de consoantes $(\mathrm{F}=4,263$; $\mathrm{p}<0,05)$. Para o segundo grupo de ouvintes, apenas a categoria desvios de acentuação foi significativa $(F=5,96$; $\mathrm{p}<0,01)$.

Considerando os resultados quantitativos, podemos responder as duas perguntas de pesquisa apresentadas na introdução.

(1) Quais desvios de pronúncia produzidos pelos aprendizes brasileiros de inglês afetam a inteligibilidade da fala desses aprendizes quando apresentada para os dois grupos de ouvintes? Para o primeiro grupo, as categorias desvios de acentuação de palavras, desvios resultantes da interferência da grafia e produção inapropriada de consoantes afetaram mais seriamente a inteligibilidade da fala dos aprendizes; para 0 segundo grupo, apenas a categoria desvios de acentuação de palavras foi significativo. Desvios de acentuação de palavras, portanto, afetaram a inteligibilidade da fala dos aprendizes para os dois grupos de ouvintes.

(2) Para qual dos dois grupos de ouvintes a pronúncia dos aprendizes é mais inteligível? Uma vez que para o grupo de ouvintes não familiarizado com o falar em inglês dos brasileiros, três categorias de desvios afetaram mais seriamente a inteligibilidade da fala dos aprendizes, e para o grupo familiarizado apenas uma categoria de desvio afetou a inteligibilidade da fala dos aprendizes, é possível afirmar que a pronúncia dos aprendizes brasileiros deste estudo é mais inteligível para o grupo de ouvintes familiarizado com o falar em inglês dos brasileiros. Esse resultado corrobora aqueles apresentados no estudo desenvolvido por Smith e Bisazza (1982) e confirma os argumentos apresentados por Field (2003) (vide item "Variáveis relacionadas aos ouvintes" neste artigo), em que falantes de inglês com um sotaque em particular são mais inteligíveis para ouvintes familiarizados com esse sotaque.

\section{Análise qualitativa}

O objetivo da análise qualitativa foi identificar como os ouvintes tinham escrito os vocábulos contendo desvios de pronúncia, e as possíveis razões que influenciaram essas transcrições. Resultados envolvendo as categorias de desvios que foram estatisticamente relevantes serão mostrados. Apresentaremos, inicialmente, as respostas dos ouvintes relacionadas à nacionalidade dos aprendizes participantes.

Como mencionado na coleta de dados (vide item "Coleta de dados" neste artigo), a fim de obter mais uma confirmação em relação à falta ou não de familiaridade dos ouvintes do primeiro grupo com o falar em inglês dos brasileiros, solicitamos, no início da conversa que tivemos com cada um deles ao final da coleta de dados, que os

\footnotetext{
${ }^{5}$ Os intervalos para cada categoria foram calculados com base na variabilidade da freqüência de desvios de pronúncia nas amostras.
} 
mesmos deduzissem a nacionalidade dos falantes que tinham ouvido. Nenhum deles mencionou brasileiro ou português como provável nacionalidade. Dez nacionalidades foram sugeridas. Excluindo 'América Latina', as restantes são principalmente européias. 'Francês' e 'espanhol' são mencionadas pela maioria dos ouvintes. Alguns ouvintes fizeram comentários, transcritos a seguir, a respeito das razões que os levaram a sugerir algumas nacionalidades ${ }^{6}$ :

Ouvinte 20: “Spanish. I’ve heard Spanish people before”.

Ouvinte 23: “Czechoslovakia and Romania”.

Researcher: "why?”

Ouvinte 23: "maybe I've heard ... people before, erm you, you hear people on the television, er like refugees being interviewed don't you, and it sounded that sort of accent to me".

Esses comentários mostram que os ouvintes associaram a pronúncia dos participantes a sotaques que eles tinham ouvido anteriormente.

Assim como com os ouvintes do primeiro grupo, solicitamos aos do segundo grupo que deduzissem a nacionalidade dos falantes que tinham ouvido. Todos eles mencionaram que havia brasileiros entre os falantes. Outras nacionalidades mencionadas foram 'espanhol' e 'italiano'. Os comentários, transcritos a seguir, mostram as razões que os levaram a sugerir brasileiros:

Ouvinte 2: "Because when they speak the 'l', for example the word 'Brazil' $[\Omega \square \star \Delta \mathscr{A}(\bullet]$, when they say, erm ... for example the word think, they say

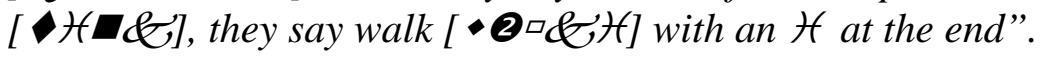

Ouvinte 10: "I guess just because I'm in Brazil... erm ... and because from the way I heard it, it's kind of that accent”.

Os comentários mostram que os ouvintes associaram a pronúncia dos aprendizes ao sotaque brasileiro, e confirmam a familiaridade com o falar em inglês dos brasileiros. A ouvinte 2, inclusive, identificou particularidades da pronúncia dos aprendizes brasileiros com as palavras 'Brazil', 'think' $e$ 'walk'. No vocábulo 'Brazil'

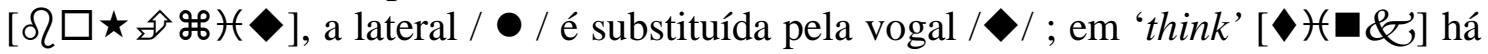

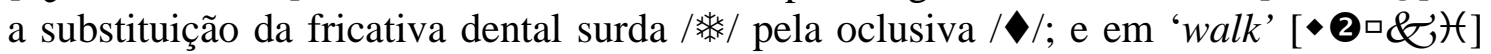
ocorre epêntese da vogal / t/.

\section{Desvios de acentuação de palavras}

A maior parte dos vocábulos contendo desvios de acentuação foi compreendida incorretamente pelos ouvintes dos dois grupos. Esse fato corrobora os resultados

\footnotetext{
${ }^{6}$ As notações para as transcrições ortográficas dos comentários são as seguintes: uma pausa ... (três pontos); uma parada rápida com entoação descendente . (um ponto) e entoação ascendente indicando continuação, (uma vírgula).
} 
obtidos na análise quantitativa apresentada anteriormente. Três exemplos serão apresentados a seguir.

(1) A amostra "it's very interesting", produzida como $[\mathcal{H} \cdot \square)($

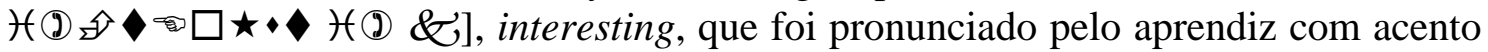
na segunda sílaba ao invés da primeira, foi escrito de várias formas pelos dois grupos de ouvintes: "it's very thirsty”, “it's very tasty”, "it's very touristy”, pelo primeiro grupo; e "it's very very sick", "he's very thirsty”, "it's very sick” pelo segundo grupo.

(2) "Meat eh fish vegetables", pronunciado como

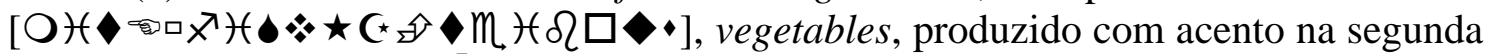
ao invés da primeira sílaba ${ }^{7}$, foi percebido de várias formas: "I eat fish at the tables", "I eat fish with the tails", "I eat fish ... terrible" por ouvintes do primeiro grupo; e "we need to switch the tables", "I need to finish the tables", "we need to fix the tables" pelos do segundo grupo.

(3) Em "the the winter is terrific", pronunciado como

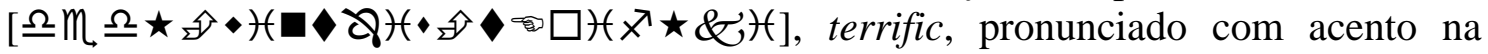
primeira sílaba ao invés da segunda, foi escrito de várias formas: "the winter is terrible"; "the winter is stuck"; "the winter is terrifying" por ouvintes do primeiro grupo; e "in winter it's terrible", "the winter is stealth" pelos do segundo.

As transcrições das três amostras acima sugerem um aspecto relevante relacionado à pista fonética que os ouvintes podem ter tido para deduzir as palavras que escreveram: a sílaba nas palavras produzidas pelos aprendizes em que o acento é colocado corresponde a uma nova palavra mal compreendida pelos ouvintes. A evidência é o primeiro som que inicia a nova palavra escrita pelos ouvintes:

interesting [H(D)

vegetables $[\star \star(\star \Delta) \mathrm{m})(\mathrm{v} \Omega \bullet \bullet]-$ at/your/two table(s), terrible, with the tails;

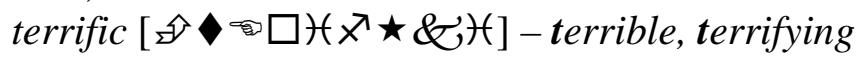

Essa evidência, apesar de limitada, pode sugerir que desvios de acentuação serviram como fronteira entre duas palavras.

Apesar da maior parte dos vocábulos contendo desvios de acentuação ter sido compreendida incorretamente pela maioria dos ouvintes dos dois grupos, alguns deles entenderam algumas palavras corretamente. No entanto, as explicações dadas para justificar a correta compreensão são diferentes: enquanto que alguns ouvintes do primeiro grupo, não familiarizados com o falar em inglês dos brasileiros, utilizam o contexto lingüístico e pistas fonéticas, os do segundo mencionam a familiaridade com a forma de pronunciar dos aprendizes brasileiros. Explicações referentes à compreensão correta da amostra 7, "meat eh fish vegetables"

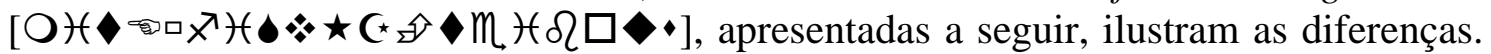
Os ouvintes 23, do primeiro grupo, e 4, do segundo, forneceram as seguintes explicações respectivamente:

Ouvinte 23: “ I didn't really understand meat as such. I didn't ... but then he said fish. and then I thought ... oh, he must have said meat first, because I linked ... because it sounded like a list erm and then he said vegetables, which I knew was wrong, but I knew what he meant. I understood. so the meat part wasn't

${ }^{7} \mathrm{~A}$ produção do acento na segunda ao invés da primeira sílaba refere-se à variedade do aprendiz. 
very clear. that word wasn't very clear. but I guessed. and it sounded it was an i sound. so I guessed”.

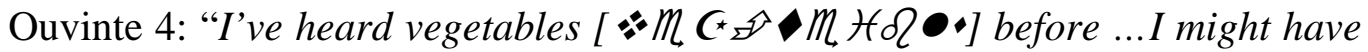
heard Brazilians before, but I think it's mainly just that ... I mean erm ... I've been here for six months and I've had to learn how to adapt really quickly and trying to...erm think about how English words might be pronounced and how they could be pronounced in different ways".

O ouvinte 23 fornece uma explicação detalhada de como ele foi capaz de deduzir e organizar os vocábulos da amostra com a ajuda do contexto lingüístico e de pistas fonéticas. A palavra 'fish', a primeira que ele foi capaz de compreender, serviu como pista para ajudá-lo a deduzir que a amostra 7 seria uma lista de itens alimentícios; 'fish', portanto, é o contexto lingüístico explorado por esse ouvinte para deduzir que a amostra incluiria itens alimentícios. Apesar de perceber que 'vegetables' não foi pronunciado corretamente, ele conseguiu compreender a palavra. O som [터, produzido de forma reduzida, do vocábulo 'meat' serviu como uma pista fonética, que, juntamente com o contexto lingüístico, auxiliou o ouvinte a deduzir essa palavra. Apesar da vogal em 'meat' ter sido pronunciada inapropriadamente, $[\mathcal{H}$ ] ao invés de $/ \mathcal{H}(\mathrm{F} /$, (ver Anexo), ela serviu como uma pista fonética para o ouvinte 23, possivelmente porque [OH $(\bullet$ ] não soa tão diferente de $/ \mathrm{O})(\square /$. O comentário desse ouvinte mostra como ele se esforçou para usar pistas disponíveis, compensar a pronúncia inadequada de vocábulos e construir a amostra 7 corretamente.

O ouvinte 4, ao contrário, afirma já ter ouvido a pronúncia

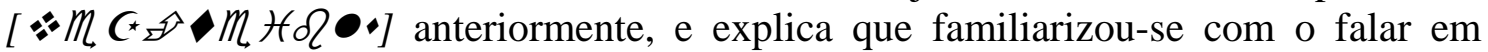
inglês dos brasileiros pela necessidade de adaptação no Brasil.

\section{Produção inapropriada de consoantes}

Diferentemente dos vocábulos contendo desvios de acentuação, a maior parte das palavras com produção inapropriada de consoantes foi compreendida incorretamente apenas pelos ouvintes do primeiro grupo.

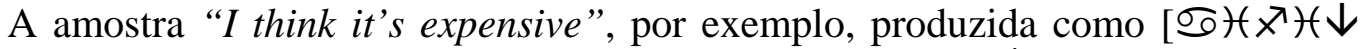

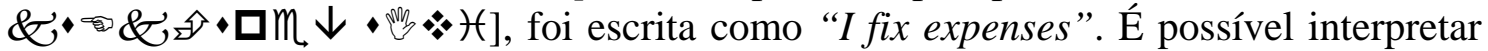
que o vocábulo 'fix' substitui 'think it's', que na transcrição fonética corresponde a $\left[\nearrow^{\top}\right)(\downarrow \& \bullet \cdot$. A produção inapropriada das consoantes que podem ter influenciado os ouvintes incluem: (1) a fricativa dental surda de 'think' produzida como [ $\left.x^{\top}\right]$, já que o ouvinte escreveu ' $f i x$ ', (2) a omissão da nasal velar / $/$ /, uma vez que 'fix' não contem nasal; e (3) “it’s”, pronunciado como [•], que juntamente com [ $\left.x^{\beth}\right)(\downarrow \& \mathcal{\&}$ ] soa como 'fix'. Essa interpretação pode ser reforçada observando-se a aproximação dos sons

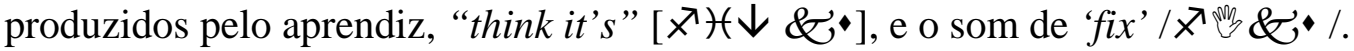

A maior parte dos ouvintes do segundo grupo compreendeu "I think it's expensive” corretamente. Alguns relacionaram a compreensão correta com fatores relacionados à familiaridade com a forma que brasileiros produzem o som da grafia $<$ th $>$, como mostram as explicações dadas pelos ouvintes 3 e 6 :

Ouvinte 3: "I know the way Brazilians pronounce words in English...erm for example th ... when there's a th in a word Brazilians tend to find that difficult". 
Ouvinte 6: "Brazilians don't make the th sound very well”.

\section{Desvios resultantes da interferência da grafia}

Assim como com os vocábulos contendo produção inapropriada de consoantes, a maioria daqueles contendo desvios resultantes da interferência da grafia foram compreendidos incorretamente pelos ouvintes do primeiro grupo.

$\mathrm{Na}$ amostra "I think it's the the smallest eh capital in Brazil"

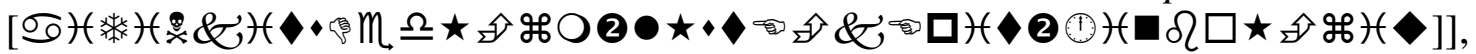
a lateral [๑] em Brazil foi produzida como [ $\bullet$ ]. Esse vocábulo foi compreendido pelos ouvintes do primeiro grupo como keeps you, through you, versus you, of you, group. Uma vez que a vogal / $/$ / e / / podem ser encontradas em you e group, os ouvintes podem ter percebido a vogal [ $\bullet$ ] em Brazil como uma pista fonética. Uma das transcrições é "I think it is the smallest cattle versus you".

Os ouvintes do segundo grupo não foram capazes de explicar claramente a razão de terem compreendido corretamente a maior parte dos vocábulos contendo desvios resultantes da interferência da grafia. Duas ouvintes, 4 e 8 , forneceram as seguintes explicações para justificar a compreensão correta do vocábulo public na amostra "The good programs are in the cable TV the others are are in the public TV"

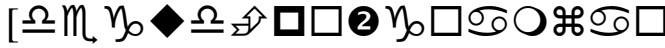

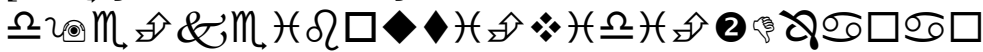

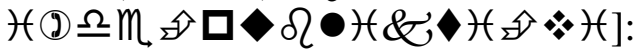

Ouvinte 4: "I just could figure out I ... you get to know ... I mean ... being in a foreign country I had to learn how to ... kind of ...just figure out what people might be saying... I keep asking what're you saying, what're you saying, what're you saying, ...trying to figure out as quickly as possible".

Ouvinte 8: “I think I’ve heard before”.

\section{Considerações finais}

Os resultados quantitativos deste estudo mostram que para o grupo de ouvintes não familiarizados com o falar em inglês dos brasileiros três desvios de pronúncia afetaram mais seriamente a inteligibilidade da fala dos aprendizes participantes: desvios de acentuação de palavras, desvios resultantes da interferência da grafia e produção inapropriada de consoantes. Para o grupo de ouvintes familiarizados com o falar em inglês de brasileiros apenas o desvio de acentuação de palavras afetou a inteligibilidade da fala dos aprendizes. A análise qualitativa corrobora esses resultados, e particulariza, através dos exemplos apresentados aqui, os desvios de pronúncia que influenciaram a compreensão dos ouvintes, bem como aspectos relacionados à familiaridade com a forma de pronunciar de aprendizes brasileiros de inglês que facilitaram a compreensão dos ouvintes do segundo grupo. Baseando-nos nesses resultados, sugerimos que desvios de acentuação de palavras, que afetaram a inteligibilidade da fala dos aprendizes até para ouvintes familiarizados com o falar em inglês dos brasileiros, podem ser considerados uma fonte de ininteligibilidade, e devem ser focalizados em aulas de pronúncia de ILE. 


\section{Referências}

ABERCROMBIE, David. Problems and principles in language study. London: Longman, 1956.

BAMGBOSE, Ayo. Torn between the norms: innovations in world Englishes. World Englishes, v. 17, n. 1, p. 1-14, 1998.

BAPTISTA, Barbara. Frequent pronunciation errors of Brazilian learners of English. In: FORTKAMP, M.; XAVIER, R. (Orgs.). EFL teaching and learning in Brazil: theory and practice. Florianópolis: Insular, 2001. p. 223-230.

BARBETTA, Pedro. Estatística aplicada às ciências sociais. Florianópolis: Editora da UFSC, 2003.

CATFORD, John. Intelligibility. English Language Teaching Journal, v. 1, n. 1, p. 7$15,1950$.

COOL EDIT [Computer Software]. USA: Syntrillium Corporation, 2000.

FIELD, John. The fuzzy notion of 'intelligibility': a headache for pronunciation teachers and oral testers. IATEFL Special Interest Groups Newsletter, Special issue, p. 34-38, 2003.

JENKINS, Jennifer. Phonology of English as an international language: new models, new norms, new goals. Oxford: Oxford University Press, 2000.

JENNER, Bryan. Teaching pronunciation: the common core. Speak out! Newsletter of the IATEFL Pronunciation SIG, v. 4, p. 2-4, 1989.

KENWORTHY, Joanne. Teaching English pronunciation. London: Longman, 1987.

LESSA, Angela A ortografia como um fator de interferência da pronúncia do inglês como língua estrangeira. 1985. Dissertação (Mestrado em Lingüística Aplicada) Pontifício Universidade Católica, São Paulo, 1985.

LIEFF. Camila; NUNES, Zaina. English pronunciation and the Brazilian learner: how to cope with language transfer. Speak Out! Newsletter of the IATEFL Pronunciation SIG, v. 12, p. 22-27, 1993.

MASCHERPE, Mario Análise comparativa dos sistemas fonológicos do inglês e do português . São Paulo: Empresa Gráfica da Revista dos Tribunais S.A., 1970.

SMITH, Larry; BISAZZA, John. The comprehensibility of three varieties of English for college students in seven countries. Language Learning, v. 32, n. 2, p. 259-269, 1982. 
SMITH, Larry; NELSON, Cecil. International intelligibility of English: directions and resources. World Englishes, v. 4, n. 3, p. 333-342, 1985.

TOMIYAMA, Machiko. Grammatical errors and communication breakdown. TESOL Quarterly, v. 14, n. 1, p. 71-79, 1980.

WANG, Yue. The intelligibility of Malaysian English: a study of some features of spoken English produced by university students in Malaysia. 1987. Tese - Universidade de Londres, Londres, 1987.

\section{Anexo}

\section{Amostra 1}

You talk about food all day

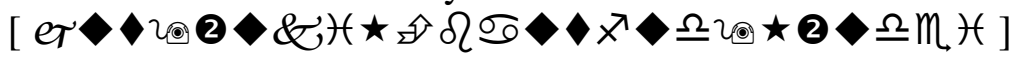

\section{Amostra 2}

It's a good place to live in

$\left[x \bullet \cdot \sigma y_{0} \wedge \Omega \square \bullet m\right)(\bullet \bullet \bullet) \cdot$ ]

Amostra 3

I think it's expensive

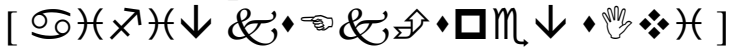

\section{Amostra 4}

I say sometimes that I I'm don't have culture

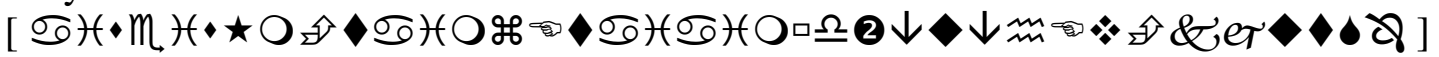

\section{Amostra 5}

In the evenings I I walk

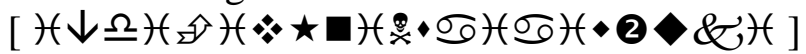

\section{Amostra 6}

My sister came to live with me. I had to learn how to live with her [

Oб)

$\bullet)(*)+m Q \nabla]$

\section{Amostra 7}

Meat eh fish vegetables

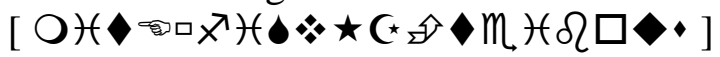

\section{Amostra 8}

To play volleyball basket at university

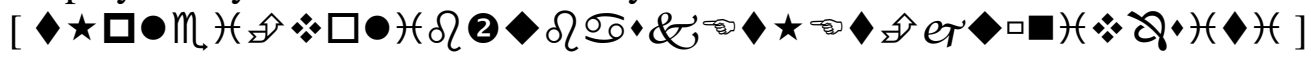


Amostra 9

I'm on the third semester

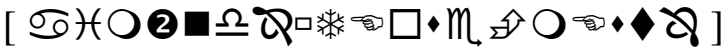

\section{Amostra 10}

The good programs are in the cable TV the others are are in the public TV

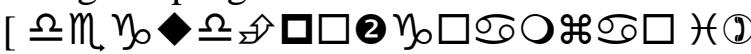

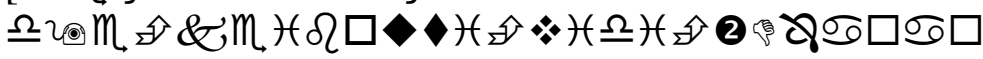

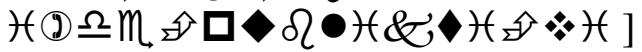

Amostra 11

You have to walk

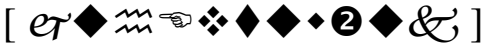

Amostra 12

I has three dogs and the first

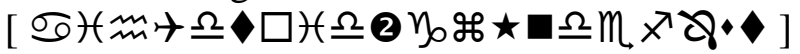

\section{Amostra 13}

We we learn about the other culture

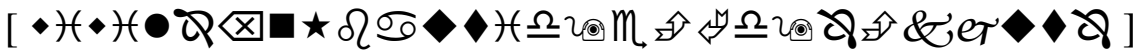

\section{Amostra 14}

It's very interesting

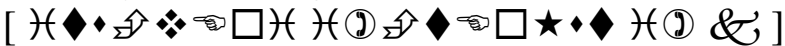

\section{Amostra 15}

She's I think near thirty years old

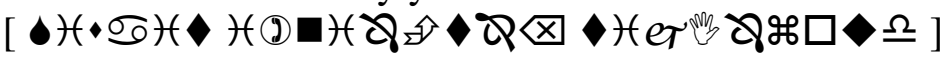

Amostra 16

Introduction to automation engineering

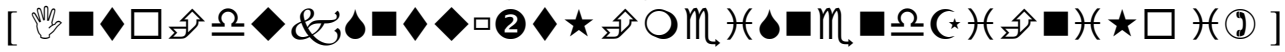

\section{Amostra 17}

It's not bringing a lot of culture to people

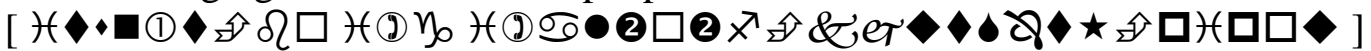

\section{Amostra 18}

Hamburger that's my my sin

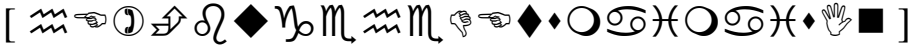

Amostra 19

Just sit and talk with my friends

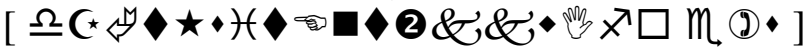

Amostra 20

eh we don't have time to read

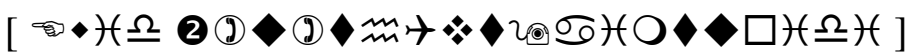




\section{Amostra 21}

They said that I'm eh very old to live with my parents

[

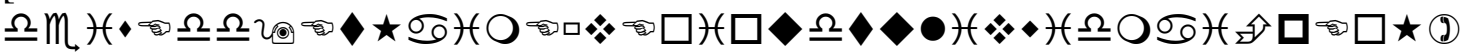

$\diamond$ ]

Amostra 22

You need to talk with someone

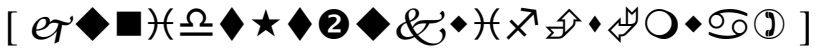

Amostra 23

It's the the biggest channel

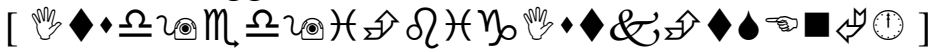

\section{Amostra 24}

A great production of agriculture

$[$ б

\section{Amostra 25}

If you don't have cable TV it's terrible

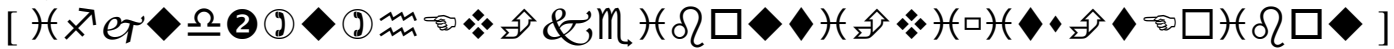

\section{Amostra 26}

Fish I like a lot

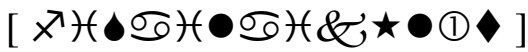

\section{Amostra 27}

In Italy the the Roman culture

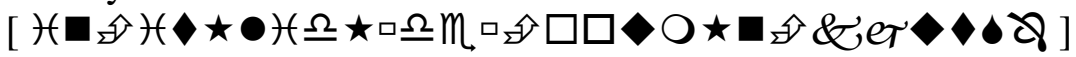

\section{Amostra 28}

The the winter is terific

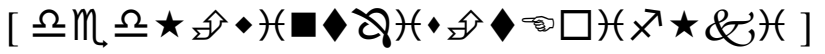

\section{Amostra 29}

Everything is easy

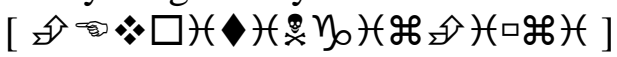

\section{Amostra 30}

I think it's the the smallest eh capital in Brazil

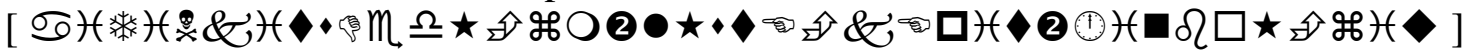

